\title{
Kidney growth curves in healthy children from the third trimester of pregnancy until the age of two years. The Generation R Study
}

\author{
J. J. Miranda Geelhoed • H. Rob Taal • Eric A. P. Steegers • Lidia R. Arends • \\ Maarten Lequin • Henriëtte A. Moll • Albert Hofman • Albert J. van der Heijden • \\ Vincent W. V. Jaddoe
}

Received: 31 July 2009 /Revised: 2 September 2009 / Accepted: 16 September 2009/Published online: 7 November 2009

(C) The Author(s) 2009. This article is published with open access at Springerlink.com

\begin{abstract}
Information about growth of kidney structures in early life is limited. In a population-based prospective cohort study, from foetal life onwards, we constructed reference curves for kidney growth from the third trimester of pregnancy until early childhood, using data from 1,158 healthy children. Kidney size, defined as length, width, depth and volume, was measured in the third trimester of pregnancy and at the postnatal ages of 6 months and 24 months. Analyses were based on more than 2,500 kidney measurements. In the third trimester of pregnancy and at 6 months of age all kidney measurements were larger in boys than in girls. At 24 months of age, these gender differences were only significant for left kidney structures
\end{abstract}

Electronic supplementary material The online version of this article (doi:10.1007/s00467-009-1335-2) contains supplementary material, which is available to authorised users.

J. J. M. Geelhoed $\cdot$ H. R. Taal • V. W. V. Jaddoe $(\square)$

The Generation R Study Group (AE-006),

Erasmus Medical Center,

P.O. Box 2040, 3000 CA Rotterdam,

The Netherlands

e-mail: v.jaddoe@erasmusmc.nl

J. J. M. Geelhoed $\cdot$ H. R. Taal $\cdot$ A. Hofman $\cdot$ V. W. V. Jaddoe

Department of Epidemiology,

Erasmus Medical Center,

Rotterdam, The Netherlands

J. J. M. Geelhoed $\cdot$ H. R. Taal $\cdot$ H. A. Moll •

A. J. van der Heijden • V. W. V. Jaddoe

Department of Pediatrics, Erasmus Medical Center,

Rotterdam, The Netherlands and right kidney length. Both groups showed trends towards smaller left kidney measurements than right kidney measurements at all ages. Gender-specific reference curves based on post-conceptional and postnatal ages were constructed for left and right kidney length, width, depth and volume. We concluded that kidney size is influenced by age and gender. Left kidney size tended to be smaller than right kidney size, except for kidney length. The reference curves can be used for assessing kidney structures by ultrasound in foetal life and early childhood.

Keywords Kidney dimensions · Reference growth curves · Children · Ultrasound · Gender

E. A. P. Steegers

Department of Obstetrics \& Gynecology,

Erasmus Medical Center,

Rotterdam, The Netherlands

\section{R. Arends}

Department of Biostatistics, Erasmus Medical Center,

Rotterdam, The Netherlands

L. R. Arends

Department of Psychology, Erasmus Medical Center,

Rotterdam, The Netherlands

M. Lequin

Department of Radiology, Erasmus Medical Center,

Rotterdam, The Netherlands 


\section{Introduction}

Assessment of kidney size in children is important for clinical and epidemiological studies. Abnormal early kidney development may have perinatal and neonatal consequences [1]. Smaller foetal kidney size has also been suggested to be related to hypertension and renal disease in adulthood [2, 3]. Recently, we showed in the same cohort that small kidney size in foetal life tends to persist in early childhood. Furthermore, maternal anthropometric characteristics, foetal biometric data and blood flow patterns were associated with kidney size in childhood. Higher growth rates in early childhood were positively associated with combined kidney volume [4]. These results suggest that variations in foetal and early postnatal exposure and growth might have persistent consequences for kidney size. Kidney size can be measured non-invasively and efficiently with ultrasound. Few studies have published reference ranges for kidney size in healthy children during foetal and neonatal life $[5,6]$. One study showed reference data on postnatal kidney growth from birth to 18 months of age [7]. Previous studies were based on the characteristics of postnatal kidney growth and focused mostly on kidney volume in relation to weight, height or body surface area. Recently, new reference centiles were generated to assess kidney size of children with 'single kidneys' to identify those patients with unfavourable courses and relevant single kidney growth impairment [8]. Currently, there are no studies that have evaluated normal kidney growth from late foetal life to early childhood. This perinatal period may be of importance in the identification of abnormal kidney size and growth, with subsequent short-term and long-term clinical consequences [9, 10].

Therefore, the aim of this study was to construct reference curves for kidney structures including kidney length, width, depth and volume in children from the third trimester of pregnancy until the postnatal age of 24 months in a population-based cohort.

\section{Methods}

\section{Study design}

This study was embedded in the Generation R Study, a population-based prospective cohort study from foetal life until young adulthood in Rotterdam, The Netherlands [11, 12]. Detailed assessments of foetal and postnatal growth and development were conducted in a subgroup of 1,232 mothers and their children [11, 12]. In this subgroup foetal kidney ultrasounds were performed in the third trimester of pregnancy (gestational age 30 weeks) and postnatal kidney ultrasounds were performed at the ages of 6 months and
24 months. The study was approved by the Medical Ethics Committee of the Erasmus MC, Rotterdam. Written informed consent was obtained from all participants.

Population for analysis

In total, 1,232 women were enrolled in the Focus cohort. The analysis was limited to singleton live-born infants $(n=$ $1,215)$ whose mothers had participated in the third trimester measurements. Twin pregnancies $(n=15)$ and pregnancies leading to perinatal death $(n=2)$ were excluded from the analysis. Kidney ultrasounds were successfully performed in $95 \%(n=1,158)$ of these subjects. Of the initial 1,215 singleton live-born infants, $74 \%(n=901)$ and $70 \%(n=856)$ underwent postnatal assessment at the ages of 6 months and 24 months, respectively. Kidney ultrasounds were successfully performed in $83 \%(n=747)$ and $80 \%(n=683)$ of these infants, respectively. Missing values were mainly due to the infants crying or to the unavailability of equipment or radiographer. Infants who had undergone a postnatal kidney ultrasound at the ages of 6 months and 24 months did not differ from the postnatal non-responders in foetal and birth characteristics. There were no kidney or ureterovesical anomalies other then mild pyelectasis over $10 \mathrm{~mm}(n=3)$ in our study population. In total, analyses were based on more than 2,500 kidney measurements. The numbers of kidney growth measurements available for the analyses are shown in Table 1.

\section{Ultrasound measurements}

Gestational age was established by foetal ultrasound. Crownrump length was used for pregnancy dating until a gestational age of 12 weeks and 5 days (crown-rump length smaller than $65 \mathrm{~mm}$ ), and biparietal diameter was used for pregnancy dating thereafter (gestational age from 12 weeks and 5 days onwards, biparietal diameter larger than $23 \mathrm{~mm}$ ) [13].

Foetal left and right kidneys were measured in the third trimester of pregnancy with an ATL-Philips HDI 5000 instrument (Seattle, WA, USA) equipped with a 2.0 5.0 $\mathrm{MHz}$ curved array transducer. In a sagittal plane the maximum longitudinal kidney length was measured, with the calipers placed on the outer edges of the caudal and cranial sides. Antero-posterior (kidney width) and transverse (kidney depth) diameters were measured perpendicular to each other, outer to outer, in an axial plane [14]. Values of maximum bipolar kidney length, width and depth were obtained from both the left and right kidneys. Kidney width and depth were measured at the level of the kidney hilum [14, 15]. The images were magnified to ensure optimal measurements [14]. Foetal growth characteristics (head circumference, abdomen circumference, femur length) were measures at the same visit, and foetal weight was estimated [13]. 
Table 1 Numbers of successful measurements per variable, according to age. Values are percentages (absolute number of children)

\begin{tabular}{llll}
\hline Kidney measurement & \multicolumn{2}{l}{ Successful measurements, \% (n) } & \\
\cline { 2 - 4 } & $\begin{array}{l}\text { Gestational age 30 weeks } \\
(n=1,215)\end{array}$ & $\begin{array}{l}\text { Age 6 months } \\
(n=901)\end{array}$ & $\begin{array}{l}\text { Age 24 months } \\
(n=856)\end{array}$ \\
\hline Left kidney & & $81.2(732)$ & $78.2(669)$ \\
Length & $94.9(1,153)$ & $77.2(696)$ & $72.8(623)$ \\
Width & $95.2(1,157)$ & $76.8(692)$ & $76.9(624)$ \\
Depth & $95.1(1,155)$ & $76.6(690)$ & $72.9(615)$ \\
Volume & $94.4(1,147)$ & & $81.9(701)$ \\
Right kidney & & $82.9(747)$ & $80.6(690)$ \\
Length & $94.7(1,151)$ & $82.4(742)$ & $80.6(690)$ \\
Width & $95.4(1,159)$ & $82.2(741)$ & $80.4(688)$ \\
Depth & $95.4(1,159)$ & $82.1(740)$ & \\
Volume & $94.5(1,148)$ & & \\
\hline
\end{tabular}

Postnatally, two-dimensional ultrasounds of the kidneys were performed in children at the ages of 6 months and 24 months. The examination was carried out in a quiet room with the child quietly awake in a supine position. This position was standardised to prevent differences resulting from position [14, 15]. Mean length, width and depth were calculated as the average of three measurements and used for data analysis. Foetal and postnatal kidney volumes were both calculated in cubic centimetres using the equation of an ellipsoid: volume $\left(\mathrm{cm}^{3}\right)=0.523 \times$ mean length $(\mathrm{cm}) \times$ mean width $(\mathrm{cm}) \times$ mean depth $(\mathrm{cm})[15,16]$. The infants' anthropometric parameters, including weight and length, were all measured at the ages of 1.5 months, 6 months and 24 months. Date of birth, birth weight and gender were obtained from midwife and hospital registers.

For the foetal ultrasound measurements, intra- and interobserver studies showed the intraclass correlation coefficient (ICC) to be higher than 0.98 and the corresponding coefficients of variation $(\mathrm{CV})$ to be lower than $6 \%$. Bland and Altman plots to test agreement of measurements demonstrated $95 \%$ limits of agreement to be within $10 \%$ difference from the mean of measurements, indicating good reproducibility [17]. For the postnatal ultrasound measurements, the intra-observer ICCs ranged from 0.93 (left and
Table 2 Subjects' characteristics. Differences between boys and girls were compared by independent-samples $t$-tests or by $\mathrm{X}^{2}$ tests. Values are means (standard deviation), medians (95\% range) or percentages

\begin{tabular}{llll}
\hline Characteristic & Boys & Girls & $P$ \\
\hline At the third trimester & $(n=603)$ & $(n=555)$ & \\
Gestational age (weeks) & $30.4(28.7-32.8)$ & $30.3(28.2-32.5)$ & 0.05 \\
Head circumference (cm) & $28.8(1.2)$ & $28.3(1.1)$ & $<0.001$ \\
Abdomen circumference (cm) & $26.7(1.7)$ & $26.5(1.6)$ & 0.2 \\
Femur length (cm) & $5.7(0.3)$ & $5.8(0.3)$ & 0.2 \\
Estimated fetal weight (g) & $1,632(264)$ & $1,623(252)$ & 0.7 \\
At birth & $(n=603)$ & $(n=555)$ & \\
Gestational age (weeks) & $40.3(36.2-42.4)$ & $40.3(36.1-42.4)$ & 0.9 \\
Gestational age $<37$ weeks $(\%)$ & $12(3.4)$ & $11(3.3)$ & 0.9 \\
Weight $(\mathrm{g})$ & $3,557(518)$ & $3,488(506)$ & 0.05 \\
Birth weight $<2,500 \mathrm{~g}(\%)$ & 8 & 10 & 0.6 \\
Small for gestational age $(\%)$ & 6 & 9 & 0.4 \\
At 6 months & $(n=379)$ & $(n=368)$ & \\
Age at visit (months) & $6.3(5.4-8.0)$ & $6.3(5.4-8.2)$ & 0.7 \\
Weight at visit (g) & $8,173(837)$ & $7,640(807)$ & $<0.001$ \\
Length at visit $(\mathrm{cm})$ & $69.4(2.4)$ & $67.9(2.4)$ & $<0.001$ \\
At 24 months & $(n=333)$ & $(n=350)$ & $<0.001$ \\
Age at visit (months) & $25.1(23.6-28.0)$ & $25.2(23.4-28.3)$ & 0.3 \\
Weight at visit $(\mathrm{g})$ & $12,890(1,395)$ & $12,429(1,343)$ & $88.4(3.3)$ \\
Length at visit $(\mathrm{cm})$ & $89.6(3.2)$ & & $<01$ \\
\hline
\end{tabular}


Table 3 Differences between boys and girls stratified for left and right kidney structures. Differences between boys and girls were compared by independent-samples $t$-tests. Values are means ( $95 \%$ range)

\begin{tabular}{|c|c|c|c|c|c|c|}
\hline \multirow[t]{2}{*}{ Kidney measurement } & \multicolumn{3}{|l|}{ Left kidney } & \multicolumn{3}{|l|}{ Right kidney } \\
\hline & Boys & Girls & $P$ & Boys & Girls & $P$ \\
\hline Gestational age 30 weeks & $(n=604)$ & $(n=553)$ & & $(n=603)$ & $(n=556)$ & \\
\hline Length (mm) & $39.5(32.0-47.0)$ & $38.4(32.7-45.0)$ & $<0.001$ & $39.6(32.0-46.6)$ & $38.5(32.2-45.3)$ & $<0.001$ \\
\hline Width (mm) & $21.6(17.0-28.0)$ & $21.1(16.5-26.0)$ & 0.001 & $22.4(17.0-28.0)$ & $22.0(17.0-27.6)$ & 0.02 \\
\hline Depth (mm) & $22.7(17.0-29.0)$ & $22.1(17.9-27.8)$ & 0.001 & $23.2(17.8-30.0)$ & $22.9(18.0-29.0)$ & 0.03 \\
\hline Volume $\left(\mathrm{cm}^{3}\right)$ & $10.3(5.4-17.9)$ & $9.5(5.4-15.0)$ & $<0.001$ & $11.0(5.8-18.5)$ & $10.3(5.8-16.8)$ & $<0.001$ \\
\hline Age 6 months & $(n=375)$ & $(n=358)$ & & $(n=379)$ & $(n=368)$ & \\
\hline Length (mm) & $60.1(48.6-70.4)$ & $58.6(50.0-67.4)$ & $<0.001$ & $58.8(49.7-69.3)$ & $57.5(49.5-67.6)$ & $<0.001$ \\
\hline Width (mm) & $28.2(22.3-36.4)$ & $27.6(21.6-35.7)$ & 0.01 & $28.0(21.8-35.4)$ & $27.5(21.4-36.5)$ & 0.04 \\
\hline Depth (mm) & $26.5(20.1-33.0)$ & $25.5(20.2-32.2)$ & $<0.001$ & $27.8(21.3-34.9)$ & $27.0(20.9-34.0)$ & 0.001 \\
\hline Volume $\left(\mathrm{cm}^{3}\right)$ & $23.8(14.0-36.6)$ & $21.9(13.9-33.4)$ & $<0.001$ & $24.0(15.3-35.6)$ & $22.4(14.2-34.6)$ & $<0.001$ \\
\hline Age 24 months & $(n=330)$ & $(n=318)$ & & $(n=347)$ & $(n=336)$ & \\
\hline Length (mm) & $66.8(56.1-80.3)$ & $65.7(53.7-78.0)$ & 0.03 & $65.2(54.8-76.6)$ & $64.3(53.2-76.5)$ & 0.04 \\
\hline Width (mm) & $30.8(25.6-37.1)$ & $30.1(23.5-37.8)$ & 0.01 & $30.7(25.6-38.0)$ & $30.6(25.2-37.1)$ & 0.61 \\
\hline Depth (mm) & $30.9(24.8-38.9)$ & $30.1(24.2-38.1)$ & 0.002 & $32.0(25.5-39.4)$ & $31.9(25.9-39.6)$ & 0.79 \\
\hline Volume $\left(\mathrm{cm}^{3}\right)$ & $33.6(22.8-51.6)$ & $31.8(19.3-52.2)$ & 0.004 & $33.8(22.9-53.3)$ & $33.1(22.1-49.2)$ & 0.19 \\
\hline
\end{tabular}

right renal widths and right renal thickness) to 0.99 (left renal length), and interobserver ICCs ranged from 0.64 (right renal thickness) to 0.90 (right renal length). Limits of agreement in the Bland and Altman plots ranged from $-8.0 \%$ to $9.2 \%$ (intra-observer left renal width) to the widest limit from $-18.0 \%$ to $19.2 \%$ (interobserver left renal length) [18].

\section{Data analysis}

Differences in foetal and postnatal characteristics between boys and girls were assessed by $t$-tests and chi-square tests for independent samples. Differences between left and right kidney were tested with paired-samples $t$-tests.

Table 4 Differences between left and right kidney structures stratified for gender. Differences between left and right kidney structures were compared using paired-samples $t$-tests. Values are means (95\% range)

\begin{tabular}{|c|c|c|c|c|c|c|}
\hline \multirow[t]{2}{*}{ Kidney measurement } & \multicolumn{3}{|l|}{ Boys } & \multicolumn{3}{|l|}{ Girls } \\
\hline & Left kidney & Right kidney & $P$ & Left kidney & Right kidney & $P$ \\
\hline Gestational age 30 weeks & $(n=604)$ & $(n=603)$ & & $(n=553)$ & $(n=556)$ & \\
\hline Length $(\mathrm{mm})$ & $39.5(32.0-47.0)$ & $39.6(32.0-46.6)$ & 0.79 & $38.4(32.7-45.0)$ & $38.5(32.2-45.3)$ & 0.45 \\
\hline Width (mm) & $21.6(17.0-28.0)$ & $22.4(17.0-28.0)$ & $<0.001$ & $21.1(16.5-26.0)$ & $22.0(17.0-27.6)$ & $<0.001$ \\
\hline Depth (mm) & $22.7(17.0-29.0)$ & $23.2(17.8-30.0)$ & $<0.001$ & $22.1(17.9-27.8)$ & $22.9(18.0-29.0)$ & $<0.001$ \\
\hline Volume $\left(\mathrm{cm}^{3}\right)$ & $10.3(5.4-17.9)$ & $11.0(5.8-18.5)$ & $<0.001$ & $9.5(5.4-15.0)$ & $10.3(5.8-16.8)$ & $<0.001$ \\
\hline Age 6 months & $(n=375)$ & $(n=379)$ & & $(n=358)$ & $(n=368)$ & \\
\hline Length (mm) & $60.1(48.6-70.4)$ & $58.8(49.7-69.3)$ & $<0.001$ & $58.6(50.0-67.4)$ & $57.5(49.5-67.6)$ & $<0.001$ \\
\hline Width (mm) & $28.2(22.3-36.4)$ & $28.0(21.8-35.4)$ & 0.50 & $27.6(21.6-35.7)$ & $27.5(21.4-36.5)$ & 0.72 \\
\hline Depth (mm) & $26.5(20.1-33.0)$ & $27.8(21.3-34.9)$ & $<0.001$ & $25.5(20.2-32.2)$ & $27.0(20.9-34.0)$ & $<0.001$ \\
\hline Volume $\left(\mathrm{cm}^{3}\right)$ & $23.8(14.0-36.6)$ & $24.0(15.3-35.6)$ & 0.35 & $21.9(13.9-33.4)$ & $22.4(14.2-34.6)$ & 0.06 \\
\hline Age 24 months & $(n=330)$ & $(n=347)$ & & $(n=318)$ & $(n=336)$ & \\
\hline Length (mm) & $66.8(56.1-80.3)$ & $65.2(54.8-76.6)$ & $<0.001$ & $65.7(53.7-78.0)$ & $64.3(53.2-76.5)$ & $<0.001$ \\
\hline Width (mm) & $30.8(25.6-37.1)$ & $30.7(25.6-38.0)$ & 0.68 & $30.1(23.5-37.8)$ & $30.6(25.2-37.1)$ & 0.02 \\
\hline Depth (mm) & $30.9(24.8-38.9)$ & $32.0(25.5-39.4)$ & $<0.001$ & $30.1(24.2-38.1)$ & $31.9(25.9-39.6)$ & $<0.001$ \\
\hline Volume $\left(\mathrm{cm}^{3}\right)$ & $33.6(22.8-51.6)$ & $33.8(22.9-53.3)$ & 0.30 & $31.8(19.3-52.2)$ & $33.1(22.1-49.2)$ & $<0.001$ \\
\hline
\end{tabular}


Fig. 1 Reference growth curves of right and left kidney length, width, depth and volume in boys and girls, according to postconceptional age. a Left kidney length, b right kidney length, c left kidney width, $\mathbf{d}$ right kidney width, e left kidney depth, f right kidney depth, $\mathbf{g}$ left kidney volume, $\mathbf{h}$ right kidney volume. Gender-

differentiated growth curves for left and right kidney length, with, depth and volume measurements in relation to post-conceptional age with 3 rd and 97 th fitted centiles. The straight lines represent boys and the dotted lines represent girls
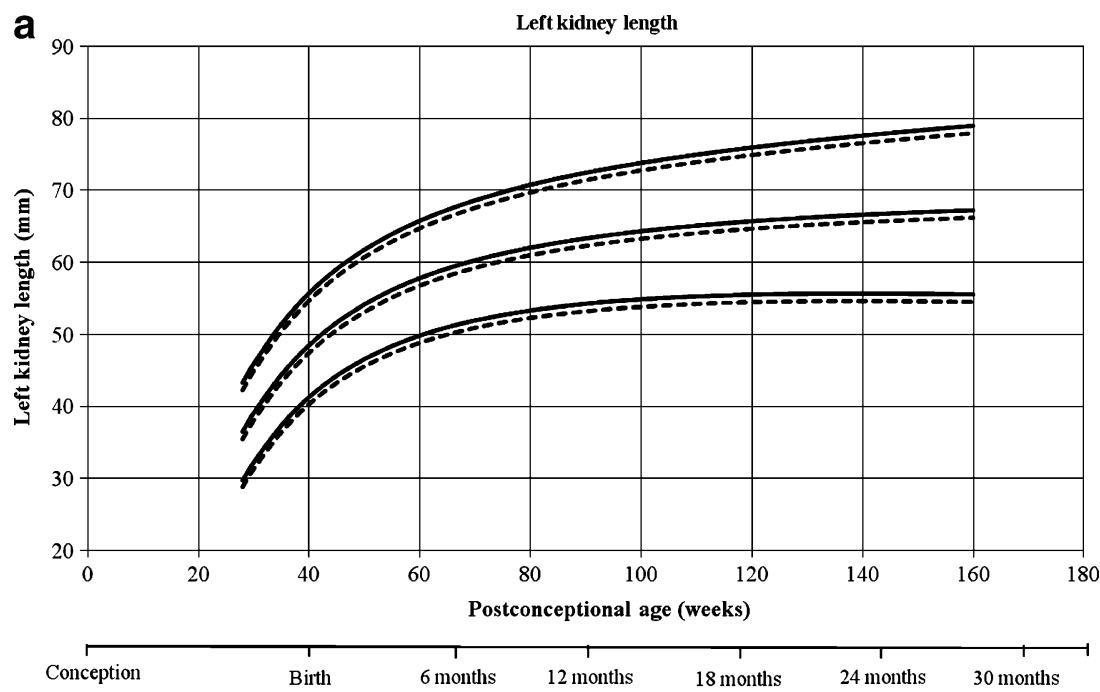

b $\quad$ Right kidney length
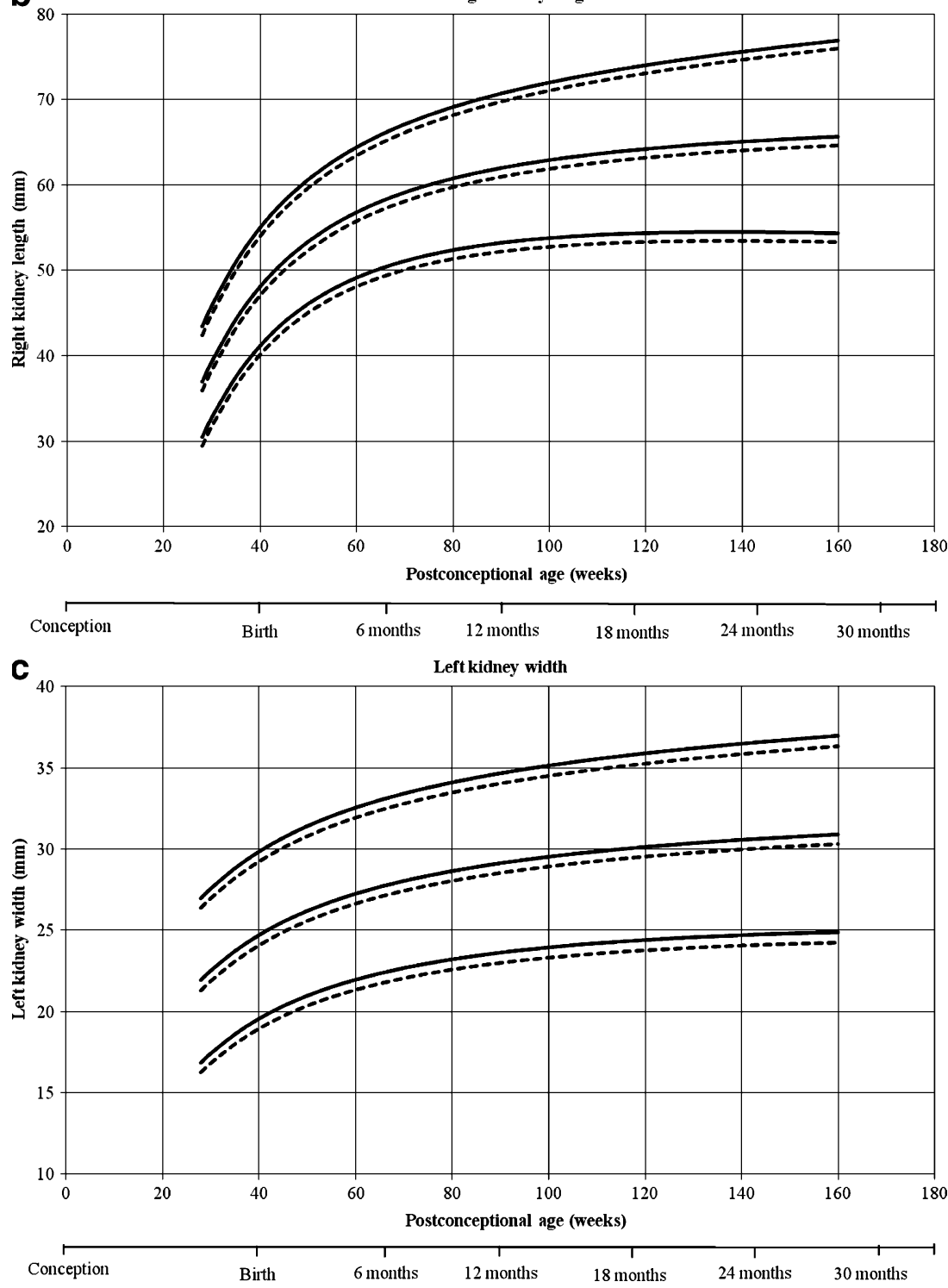
Fig. 1 (continued)
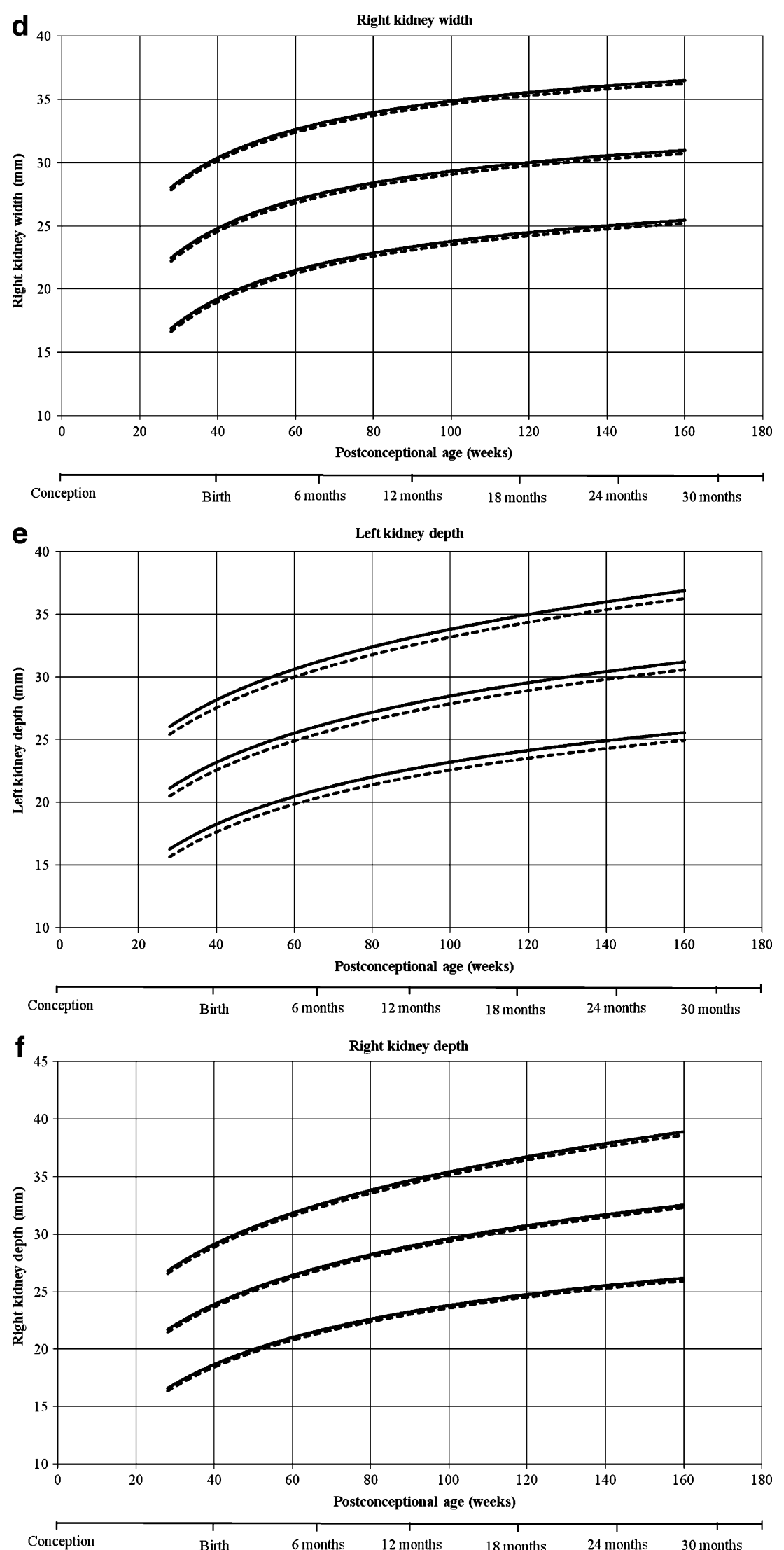
Fig. 1 (continued)
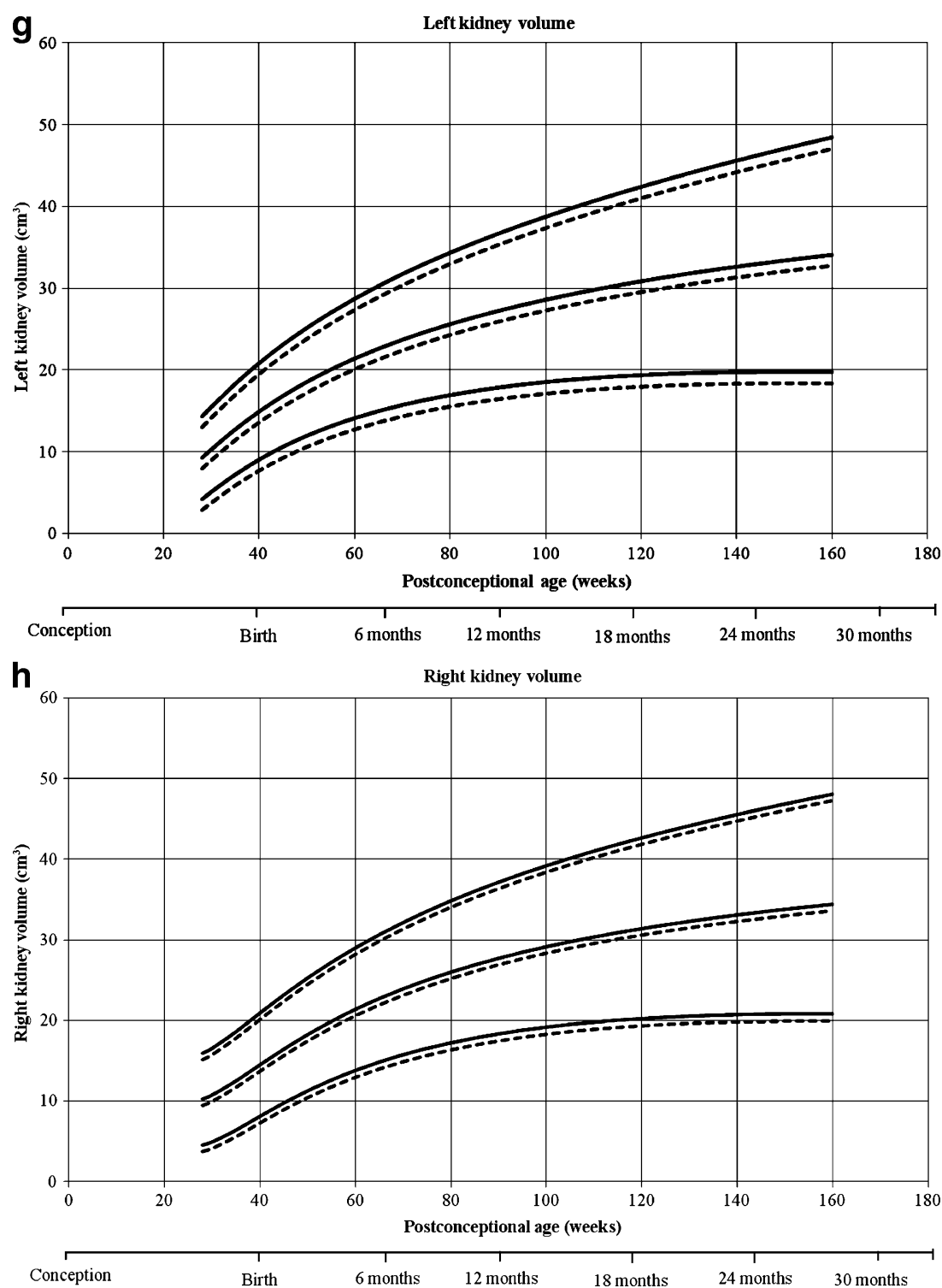

Data were analysed as recommended by Altman and Chitty [19] and Royston and Altman [20]. For the reference curves for kidney growth, post-conceptional age was plotted against kidney length, width, depth and volume. From the original data, measurements of more than two standard deviations (SDs) from the regression line, fitted on our data, were considered to be outliers $(n=10)$ and were therefore removed. They were probably a result of measurement error or a data entry error. The best-fitting curves were determined by second-degree fractional polynomials [21]. We fitted the curves, using repeated measurement analyses and taking into account the dependency in the data by specifying a constant covariance between measurements of the same subject $[20,22]$. The best-fitting fractional polynomial curves were chosen by our comparing the deviances, by Akaike's information criterion, and by our visually checking the goodness of fit. Next, regression lines were fitted for the dependency of the residual SD on conceptional age [23]. Subsequently, we plotted the SD scores against conceptional age to assess the correctness of the model.

Finally, centiles were derived and the curves were plotted on the data. The median age of 2-year-old children visiting the research centre was 25 months (95\% range 23.6-28.3 months). Since only 34 children had undergone measurement beyond the postnatal age of 28 months (160 weeks after conception), the results are presented up to the postnatal age of 28 months. Reference curves for kidney growth were constructed for a post-conceptional age from 30 weeks to 160 weeks, corresponding to a gestational age of 30 weeks and a postnatal age of 28 months.

All statistical analyses were performed with the Statistical Package for the Social Sciences, version 15.0, for Windows (SPSS Inc, Chicago, IL, USA) and the Statistical Analysis System (SAS) for Windows, version 9.1.3. 


\section{Results}

The percentage of boys was 52\% (Table 2). The overall median age at the third trimester of pregnancy was 30 weeks of gestation (total range 27.1-35.1 weeks). The overall median age of the infants at their 6-month postnatal visit was 6.3 months (total range 5.1-11.0 months), and at their 24-month postnatal visit it was 25.1 months (total range 21.6-31.6 months). Head circumference at the third trimester and postnatal weight and length at the ages of 6 months and 24 months were larger in boys than in girls (all $P$ values $<0.001$ ). No difference was found for gestational age at birth between boys and girls. In total, 15 children in our study group were born with a small size for gestational age $[<-2$ standard deviation scores (SDS)], 18 children had a low birth weight $(<2,500 \mathrm{~g})$ and 23 children were born before term (gestational age $<37$ weeks). Table 3 shows that in the third trimester of pregnancy and at the age of 6 months all kidney measurements were larger in boys than in girls. At the age of 24 months, these gender differences were only significant for left kidney structures and right kidney length. Both groups showed trends towards smaller left kidney measurements than right kidney measurements at all ages (Table 4).

Reference curves for individual measurements of kidney growth and fitted centiles are given in Fig. 1. Formulae for growth reference curves describing the mean with the corresponding standard deviation are given in Table 5. Standard deviation increased linearly with gestational age.
Reference values for kidney length, width, depth and volume are given in the Appendix (Tables $1 \mathrm{~S}-4 \mathrm{~S}$ ).

\section{Discussion}

We constructed gender-specific reference growth curves for kidney length, width, depth and volume using measurements from a large population-based prospective cohort study of healthy children followed from foetal life until early childhood. We observed differences in kidney structures between left and right kidneys and boys and girls.

The major strength of our study is its prospective design from foetal life and the size of the population-based cohort. Our reference curves were based on more than 2,500 kidney measurements. To our knowledge, no previous studies that focused on kidney size in early life were based on such large numbers. All foetal ultrasounds were carried out by two sonographers, and $86 \%$ of all postnatal ultrasounds were performed by one trained sonographer [24]. A limitation could be that in all children participating in the Generation $\mathrm{R}$ measurements at the ages of 6 months and 24 months, kidney measurements were successfully performed in $83 \%$ and $80 \%$ of these infants, respectively. Missing values were mainly due to the infants crying or to the unavailability of equipment or radiographer. Our results would have been biased if the subjects' characteristics had differed between those included and those not included in the analyses. However, we observed no differences in

Table 5 Reference curves for kidney structures: equations for the mean and SD of each measurement, based on age in exact weeks. Gender=0 for boys and gender $=1$ for girls. Age defined as post-conceptional age (weeks)

\begin{tabular}{|c|c|c|}
\hline Kidney measurement & Measurement & Regression equation \\
\hline \multicolumn{3}{|l|}{ Left kidney } \\
\hline Length (mm) & $\begin{array}{l}\text { Mean } \\
\text { SD }\end{array}$ & $\begin{array}{l}70.7392+48231 \times\left(1 / \mathrm{Age}^{2}\right)-22290 \times\left(1 / \mathrm{Age}^{2}\right) * \ln (\text { Age })-1.0112 \times \text { Gender } \\
3.033+0.020 \times \text { Age }\end{array}$ \\
\hline Width (mm) & $\begin{array}{l}\text { Mean } \\
\text { SD }\end{array}$ & $\begin{array}{l}33.9989+2465.42 \times\left(1 / \mathrm{Age}^{2}\right)-408.99 \times(1 / \text { Age })-0.6208 \times \text { Gender } \\
2.577+0.004 \times \text { Age }\end{array}$ \\
\hline Depth (mm) & $\begin{array}{l}\text { Mean } \\
\text { SD }\end{array}$ & $\begin{array}{l}2.5301+5.7694 \times \ln (\text { Age })-0.6145 \times \text { Gender } \\
2.502+0.0031 \times \text { Age }\end{array}$ \\
\hline Volume $\left(\mathrm{cm}^{3}\right)$ & $\begin{array}{l}\text { Mean } \\
\text { SD }\end{array}$ & $\begin{array}{l}56.8477+4222.85 \times\left(1 / \mathrm{Age}^{2}\right)-273.13 \times(1 / \sqrt{ } \text { Age })-1.3538 \times \text { Gender } \\
1.639+0.0375 \times \text { Age }\end{array}$ \\
\hline \multicolumn{3}{|l|}{ Right kidney } \\
\hline Length (mm) & $\begin{array}{l}\text { Mean } \\
\text { SD }\end{array}$ & $\begin{array}{l}69.05+46279 \times\left(1 / \mathrm{Age}^{2}\right)-21206 \times\left(1 / \mathrm{Age}^{2}\right) \times \ln (\text { Age })-1.0561 \times \text { Gender } \\
2.899+0.0194 \times \text { Age }\end{array}$ \\
\hline Width (mm) & $\begin{array}{l}\text { Mean } \\
\text { SD }\end{array}$ & $\begin{array}{l}37.4342+122.84 \times\left(1 / \mathrm{Age}^{2}\right)-78.8602 *(1 / \sqrt{ } \text { Age })-0.2290 \times \text { Gender } \\
2.977-0.00025 \times \text { Age }\end{array}$ \\
\hline Depth (mm) & $\begin{array}{l}\text { Mean } \\
\text { SD }\end{array}$ & $\begin{array}{l}1.2261+6.2168 \times \ln (\text { Age })-0.2474 \times \text { Gender } \\
2.576+0.005 \times \text { Age }\end{array}$ \\
\hline Volume $\left(\mathrm{cm}^{3}\right)$ & $\begin{array}{l}\text { Mean } \\
\text { SD }\end{array}$ & $\begin{array}{l}45.4105+22573 \times\left(1 / \mathrm{Age}^{2}\right)-1766.41 \times(1 / \text { Age })-0.8152 \times \text { Gender } \\
2.128+0.0321 \times \text { Age }\end{array}$ \\
\hline
\end{tabular}


growth and foetal kidney characteristics between the subjects that had undergone postnatal kidney measurement and those that had not. Another limitation could be that the study was performed in a healthy population-based cohort study. The selection towards a healthy population in our cohort might lead to a limited generalisability to preterm children or to children that were small for gestational age at birth. These numbers were too small to be assessed in further detail.

In the third trimester of pregnancy and at the age of 6 months all kidney measurements were larger in boys than in girls. At the age of 24 months, these gender differences were only significant for left kidney structures and right kidney length. Several studies of healthy neonates and adults have also shown that male subjects have larger kidneys than those of female subjects $[25,26]$. One explanation for this finding might be a growth-stimulating effect of androgens, or Y-chromosome-related genes. Another explanation could be that during foetal life testosterone levels are significantly higher in boys than in girls [27, 28].

Previously published data have shown conflicting results concerning differences between left and right kidney size. Some studies found no difference [29, 30], whereas others have suggested the left kidney to be larger [31, 32]. Most consistent findings have been reported for kidney length, for which the left kidney seems to be longer than the right $[7,25,26,31,33]$. We found that the left kidney was longer in both boys and girls at the postnatal ages of 6 months and 24 months. In foetal life we found no significant difference between left and right kidney length.

Kidney growth is fastest during foetal life and early infancy, and the rate of increase gradually slows through the remainder of the first year of life and finally stabilises [34]. In our study numbers and curves for the 3rd centiles showed decreasing kidney volume at older ages, from 140 weeks and onwards. The decreasing numbers are due to wider ranges, because of the low number of children with visits around 140 weeks and onwards. To deal with non-linear kidney growth, some sonographic standards, including means and standard deviations, for kidney size in relation to age have been published [34-36]. A few other studies created linear or non-linear polynomial regression equations for kidney size during the first year of life [29, 33]. One study created reference material for kidney size in healthy children beyond the neonatal period [7]. The authors only focused on kidney volume in relation to weight, height and body surface area and did not report data about prenatal kidney growth. To our knowledge, our study is the first to provide prospective longitudinal reference material for kidney size that covers the whole period from foetal life to infancy in a healthy population.

In conclusion, kidney size differed between boys and girls from the age of 30 weeks of pregnancy until 24 months of age. The left kidney tended to be smaller than the right kidney. At the age of 24 months, the differences in right kidney size between boys and girls were attenuated. Genderdifferentiated reference growth curves for both left and right kidneys were constructed for kidney length, width, depth and volume. These reference curves may be of importance in the identification of abnormal kidney size and growth, with possible subsequent clinical consequences.

Acknowledgements The Generation R Study was conducted by the Erasmus Medical Center in close collaboration with the School of Law and the Faculty of Social Sciences at the Erasmus University, Rotterdam, the Municipal Health Service, Rotterdam area, the Rotterdam Homecare Foundation, and the Stichting Trombosedienst \& Artsenlaboratorium Rijnmond (STAR), Rotterdam. We gratefully acknowledge the contribution of general practitioners, hospitals, midwives and pharmacies in Rotterdam.

The first phase of the Generation R Study was made possible by financial support from the Erasmus Medical Center, Rotterdam, the Erasmus University, Rotterdam, and the Netherlands Organization for Health Research and Development (ZonMw). Additional support was provided by a grant from the Dutch Kidney Foundation (C08.2251).

The authors declare that they have no personal or financial conflicts of interest.

Open Access This article is distributed under the terms of the Creative Commons Attribution Noncommercial License which permits any noncommercial use, distribution, and reproduction in any medium, provided the original author(s) and source are credited.

\section{References}

1. O'Neill WC (2000) Sonographic evaluation of renal failure. Am J Kidney Dis 35:1021-1038

2. Brenner BM, Chertow GM (1994) Congenital oligonephropathy and the etiology of adult hypertension and progressive renal injury. Am J Kidney Dis 23:171-175

3. Keller G, Zimmer G, Mall G, Ritz E, Amann K (2003) Nephron number in patients with primary hypertension. $\mathrm{N}$ Engl J Med 348:101-108

4. Geelhoed JJ, Verburg BO, Nauta J, Lequin M, Hofman A, Moll HA, Witteman JC, van der Heijden AJ, Steegers EA, Jaddoe VW (2009) Tracking and determinants of kidney size from fetal life until the age of 2 years: the Generation R Study. Am J Kidney Dis 53:248-258

5. Gloor JM, Breckle RJ, Gehrking WC, Rosenquist RG, Mulholland TA, Bergstralh EJ, Ramin KD, Ogburn PL Jr (1997) Fetal renal growth evaluated by prenatal ultrasound examination. Mayo Clin Proc 72:124-129

6. Kennedy WA 2nd, Chitkara U, Abidari JM, Shortliffe LM (2003) Fetal renal growth as assessed through renal parenchymal area derived from prenatal and perinatal ultrasonography. J Urol 169:298-302

7. Schmidt IM, Main KM, Damgaard IN, Mau C, Haavisto AM, Chellakooty M, Boisen KA, Petersen JH, Scheike T, Olgaard K (2004) Kidney growth in 717 healthy children aged 0-18 months: a longitudinal cohort study. Pediatr Nephrol 19:992-1003

8. Spira EM, Jacobi C, Frankenschmidt A, Pohl M, von Schnakenburg C (2009) Sonographic longterm study: paediatric growth charts for single kidneys. Arch Dis Child 94:693-698

9. Pickworth FE, Carlin JB, Ditchfield MR, de Campo MP, de Campo JF, Cook DJ, Nolan T, Powell HR, Sloane R, Grimwood $\mathrm{K}$ (1995) Sonographic measurement of renal enlargement in 
children with acute pyelonephritis and time needed for resolution: implications for renal growth assessment. AJR Am J Roentgenol 165:405-408

10. Parvex P, Willi JP, Kossovsky MP, Girardin E (2008) Longitudinal analyses of renal lesions due to acute pyelonephritis in children and their impact on renal growth. J Urol 180:2602-2606

11. Jaddoe VW, Bakker R, van Duijn CM, van der Heijden AJ, Lindemans J, Mackenbach JP, Moll HA, Steegers EA, Tiemeier H, Uitterlinden AG, Verhulst FC, Hofman A (2007) The Generation R Study biobank: a resource for epidemiological studies in children and their parents. Eur J Epidemiol 22:917-923

12. Jaddoe VW, van Duijn CM, van der Heijden AJ, Mackenbach JP, Moll HA, Steegers EA, Tiemeier H, Uitterlinden AG, Verhulst FC, Hofman A (2008) The Generation R Study: design and cohort update until the age of 4 years. Eur J Epidemiol 23:801-811

13. Verburg BO, Steegers EA, De Ridder M, Snijders RJ, Smith E, Hofman A, Moll HA, Jaddoe VWV, Witteman JCM (2008) New charts for ultrasound dating of pregnancy and assessment of fetal growth: longitudinal data from a population-based cohort study. Ultrasound Obstet Gynecol 31:388-396

14. Jeanty P, Dramaix-Wilmet M, Elkhazen N, Hubinont C, van Regemorter N (1982) Measurements of fetal kidney growth on ultrasound. Radiology 144:159-162

15. Gupta AK, Anand NK, Lamba IM (1993) Ultrasound evaluation of kidney dimensions in neonates. Indian Pediatr 30:319-324

16. Konje JC, Okaro CI, Bell SC, de Chazal R, Taylor DJ (1997) A cross-sectional study of changes in fetal renal size with gestation in appropriate- and small-for-gestational-age fetuses. Ultrasound Obstet Gynecol 10:22-26

17. Verburg BO, Mulder PG, Hofman A, Jaddoe VW, Witteman JC, Steegers EA (2008) Intra- and interobserver reproducibility study of early fetal growth parameters. Prenat Diagn 28:323-331

18. Geelhoed JJ, Kleyburg-Linkers VE, Snijders SP, Lequin M, Nauta J, Steegers EA, van der Heijden AJ, Jaddoe VW (2009) Reliability of renal ultrasound measurements in children. Pediatr Nephrol 24:1345-1353

19. Altman DG, Chitty LS (1997) New charts for ultrasound dating of pregnancy. Ultrasound Obstet Gynecol 10:174-191

20. Royston P, Altman DG (1995) Design and analysis of longitudinal studies of fetal size. Ultrasound Obstet Gynecol 6:307-312

21. Royston P, Ambler G, Sauerbrei W (1999) The use of fractional polynomials to model continuous risk variables in epidemiology. Int J Epidemiol 28:964-974

22. Royston P (1995) Calculation of unconditional and conditional reference intervals for foetal size and growth from longitudinal measurements. Stat Med 14:1417-1436
23. Altman DG (1993) Construction of age-related reference centiles using absolute residuals. Stat Med 12:917-924

24. Verburg BO, Geelhoed JJ, Steegers EA, Hofman A, Moll HA, Witteman JC, Jaddoe VW (2007) Fetal kidney volume and its association with growth and blood flow in fetal life: The Generation R Study. Kidney Int 72:754-761

25. Emamian SA, Nielsen MB, Pedersen JF, Ytte L (1993) Kidney dimensions at sonography: correlation with age, sex, and habitus in 665 adult volunteers. AJR Am J Roentgenol 160:83-86

26. Scott JE, Hunter EW, Lee RE, Matthews JN (1990) Ultrasound measurement of renal size in newborn infants. Arch Dis Child 65:361-364

27. Forest MG, de Peretti E, Lecoq A, Cadillon E, Zabot MT, Thoulon JM (1980) Concentration of 14 steroid hormones in human amniotic fluid of midpregnancy. J Clin Endocrinol Metab 51:816-822

28. Wilson JD, Griffin JE, Leshin M, George FW (1981) Role of gonadal hormones in development of the sexual phenotypes. Hum Genet 58:78-84

29. Han BK, Babcock DS (1985) Sonographic measurements and appearance of normal kidneys in children. AJR Am J Roentgenol 145:611-616

30. Holloway H, Jones TB, Robinson AE, Harpen MD, Wiseman HJ (1983) Sonographic determination of renal volumes in normal neonates. Pediatr Radiol 13:212-214

31. Dinkel E, Ertel M, Dittrich M, Peters H, Berres M, SchulteWissermann H (1985) Kidney size in childhood. Sonographical growth charts for kidney length and volume. Pediatr Radiol 15:38-43

32. Schmidt IM, Molgaard C, Main KM, Michaelsen KF (2001) Effect of gender and lean body mass on kidney size in healthy 10year-old children. Pediatr Nephrol 16:366-370

33. Konus OL, Ozdemir A, Akkaya A, Erbas G, Celik H, Isik S (1998) Normal liver, spleen, and kidney dimensions in neonates, infants, and children: evaluation with sonography. AJR Am J Roentgenol 171:1693-1698

34. Vujic A, Kosutic J, Bogdanovic R, Prijic S, Milicic B, Igrutinovic Z (2007) Sonographic assessment of normal kidney dimensions in the first year of life - a study of 992 healthy infants. Pediatr Nephrol 22:1143-1150

35. Rosenbaum DM, Korngold E, Teele RL (1984) Sonographic assessment of renal length in normal children. AJR Am J Roentgenol 142:467-469

36. Zerin JM, Meyer RD (2000) Sonographic assessment of renal length in the first year of life: the problem of "spurious nephromegaly". Pediatr Radiol 30:52-57 